\title{
Phenotype Characterization and DSPP Mutational Analysis of Three Brazilian Dentinogenesis Imperfecta Type II Families
}

\author{
A.C. Acevedo ${ }^{a} \quad$ L.J.S. Santos ${ }^{a} \quad$ L.M. Paula ${ }^{a} \quad J_{\text {Dong }}{ }^{b} \quad$ M. MacDougall ${ }^{b}$ \\ a Dental Anomalies Clinic, Dentistry School, Oral Health Faculty, University of Brasilia, Brasilia, Brazil; b Institute of \\ Oral Health Research, School of Dentistry, University of Alabama at Birmingham, Birmingham, Ala., USA
}

\section{Key Words}

Dentinogenesis imperfecta type II • Phenotype •

Dentin sialophosphoprotein - Mutational analysis •

Single nucleotide polymorphisms

\begin{abstract}
The aim of this study was to perform phenotype analysis and dentin sialophosphoprotein (DSPP) mutational analysis on 3 Brazilian families diagnosed with dentinogenesis imperfecta type II (DGI-II) attending the Dental Anomalies Clinic in Brasilia, Brazil. Physical and oral examinations, as well as radiographic and histopathological analyses, were performed on 28 affected and unaffected individuals. Clinical, radiographic and histopathological analyses confirmed the diagnosis of DGI-II in 19 individuals. Pulp stones were observed in ground sections of several teeth in 2 families, suggesting that obliteration of pulp chambers and root canals results from the growth of these nodular structures. Mutational DSPP gene analysis of representative affected family members revealed 7 various non-disease-causing alterations in exons 1-4 within the dentin sialoprotein domain. Further longitudinal studies are necessary to elucidate the progression of pulpal obliteration in the DGI-II patients studied as well as the molecular basis of their disease.
\end{abstract}

Copyright $\odot 2008$ S. Karger AG, Basel

\section{KARGER}

Fax +4161306 1234

E-Mail karger@karger.ch

www.karger.com
(C) 2008 S. Karger AG, Basel

Accessible online at: www.karger.com/cto

\section{Introduction}

Genetic diseases that primarily affect dentin formation are known as heritable dentin diseases [Ranta et al., 1993; MacDougall et al., 2006]. At present, reported cases exhibit mainly an autosomal dominant mode of inheritance and are classified in 2 major groups with further subclassifications: dentin dysplasia (DD) with types I and II, and dentinogenesis imperfecta (DGI) with types I-III [Shields et al., 1973; Witkop, 1989].

DGI-II (OMIM 125490, Online Mendelian Inheritance in Man, http://www.ncbi.nlm.nih.gov), also called opalescent dentin, is the most common of the heritable dentin diseases, with an estimated prevalence in the United States between 1:6,000 and 1:8,000 [Witkop et al., 1966]. Affected patients show tooth alterations, but

\begin{tabular}{ll} 
Abbreviations used in this paper \\
\hline DD & dentin dysplasia \\
DGI & dentinogenesis imperfecta \\
DSP & dentin sialoprotein \\
DSPP & dentin sialophosphoprotein \\
SNP & single nucleotide polymorphism
\end{tabular}

Dr. Mary MacDougall

Institute of Oral Health Research, School of Dentistry

University of Alabama at Birmingham

1919 7th Ave. South, Rm 702, Birmingham, AL 35294 (USA)

Tel. +1 205996 5122, Fax +1 205996 5109, E-Mail macdougall@uab.edu 


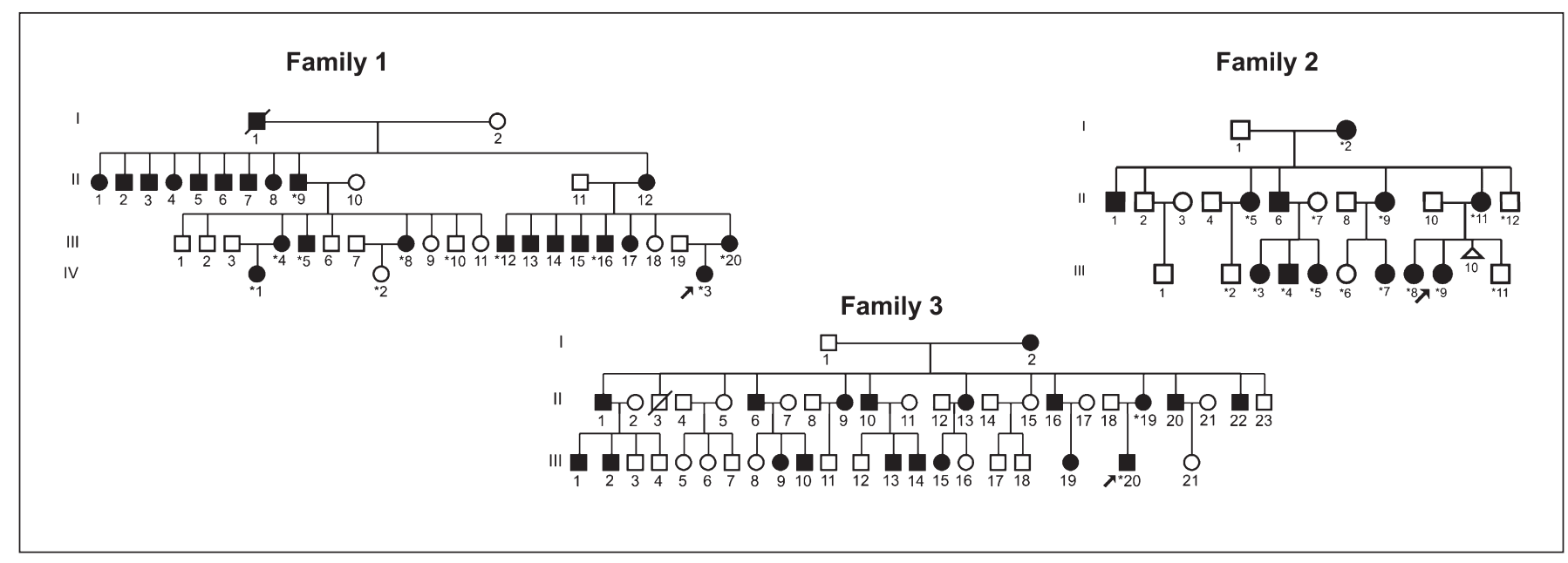

Fig. 1. Pedigrees of the three DGI-II families with arrows indicating the proband of each family. Boxes = Males; circles $=$ females; filled symbols $=$ affected family members.

do not exhibit any bone anomalies. Both deciduous and permanent teeth are affected, appearing discolored and translucent. Also, variable degrees of attrition can be observed, likely due to enamel chipping. Radiographic features include bulbous-shaped crowns resulting from cervical constrictions at the crown-root junction, altered root morphology appearing smaller and narrower, as well as pulp chamber and root canal obliteration [Rao and Witkop, 1971; Shields et al., 1973; Witkop, 1975]. The histopathological analysis of DGI-II teeth revealed an apparently normal mantle dentin, but dentinal tubules of the circumpulpal dentin were decreased in number and displayed a disorganized distribution with smaller diameters [Kerebel et al., 1981]. Also, the mineral content was altered, showing a decrease in the number of crystallites and in the total mineral content, compared with normal dentin [Kinney et al., 2001].

Among the noncollagenous proteins, dentin sialoprotein (DSP) and dentin phosphoprotein are the major proteins, and are believed to play a crucial role in dentinogenesis. These 2 proteins are derived from the cleavage of a parent 940 -amino acid polypeptide and are encoded by a single gene, dentin sialophosphoprotein (DSPP) [MacDougall et al., 1997]. In all species studied to date, the DSPP gene is organized in 5 exons and 4 introns [MacDougall et al., 1997]. DSPP knockout mice have demonstrated the critical role of this gene in normal dentin formation related to mineralization [Sreenath et al., 2003].

Phenotype/Mutational DSPP Analysis of DGI Type II Families
At present, only DSPP mutations have been associated with the pathogenesis of dentin diseases without bone involvement, including DGI-II, DGI-III and DD-II. DSPP mutations have been reported causing DD-II, DGI-II with or without progressive hearing loss [Xiao et al., 2001; Zhang et al., 2001; Rajpar et al., 2002, Kim et al., 2004, 2005; Malmgren et al., 2004; Holappa et al., 2006; Zhang et al., 2007] and DGI-III [Dong et al., 2005]. The overwhelming majority of mutations has been reported in the DSP-encoding region, especially in exons 2 and 3 . The aim of the present study was to characterize the phenotype and to perform mutational analysis of DSPP in 3 Brazilian families with DGI-II attending the Dental Anomalies Clinic in Brasília, Brazil.

\section{Materials and Methods}

\section{Family and Phenotype Analysis}

The Ethics Board of the Brazilian Ministry of Health (CONEP) approved this study and informed consent was obtained from all participants. Physical and dental examinations were performed on 28 individuals from the 3 families (family 1, family 2 and family 3). Histological examination was performed on 7 deciduous and 14 permanent teeth using light microscopy (Axiophot; Zeiss).

\section{Mutational Analysis}

Genomic DNA was extracted from whole blood using a Wizard Genomic DNA purification kit (Promega). Mutational analysis was performed by PCR and bidirectional sequencing methods. The DSP part of DSPP gene was amplified using DSPP gene-spe- 

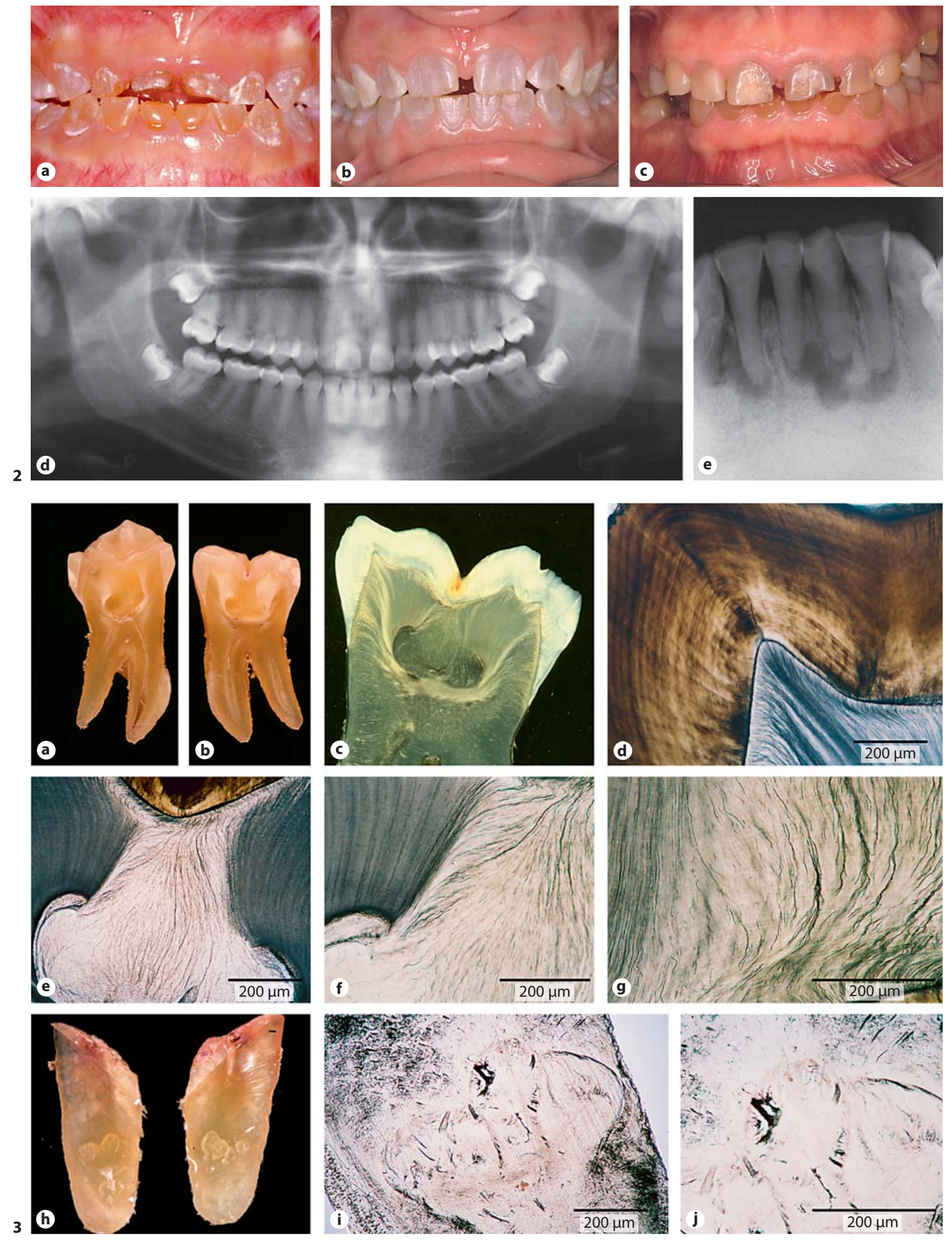
cific primers spanning exon-intron boundaries of the human DSP part of DSPP gene (primer sequences available upon request). DNA was amplified using $0.625 \mu$ l RedTaq DNA polymerase (Sig$\mathrm{ma}), 50 \mathrm{nM}$ of total dNTPs and $25 \mathrm{ng}$ DNA in a total $12.5-\mu \mathrm{l} \mathrm{reac}-$ tion with a PCR program of an initial denaturation at $94^{\circ} \mathrm{C}$ for $4 \mathrm{~min}, 10$ cycles at $94^{\circ} \mathrm{C}$ for $15 \mathrm{~s}, 62^{\circ} \mathrm{C}$ for $15 \mathrm{~s}$ with the annealing temperature dropping $1^{\circ} \mathrm{C}$ at every reaction cycle and $72^{\circ} \mathrm{C}$ for $15 \mathrm{~s}$, then 24 cycles at $94^{\circ} \mathrm{C}$ for $15 \mathrm{~s}, 55^{\circ} \mathrm{C}$ for $30 \mathrm{~s}$ and $72^{\circ} \mathrm{C}$ for $1 \mathrm{~min}$, with a final extension at $72^{\circ} \mathrm{C}$ for $10 \mathrm{~min}$. PCR products were checked on $1 \%$ agarose gel and purified by ExoSAP-IT (USB). Bidirectional DNA sequencing was performed with an ABI 3730 sequencer using BigDye version 3.1 (ABI). Standard nomenclature for sequence variations was followed (http/:www.hgvs.org).

\section{Results}

All 3 families were from the State of Bahia, Brazil. Pedigree analysis indicated an autosomal dominant pattern of inheritance for all 3 families (fig. 1). Physical examinations by trained endocrinologists did not reveal any bone pathology. No bone fractures, bone pain or ligament hyperextensibility were reported or observed in the examined patients. The clinical and radiographic features of the 3 DGI-II families are summarized in table 1. Developmental variations in the degree of dentin discoloration were observed in affected family members: yellow to brown in the deciduous dentition (fig. 2a), bluish gray in the young permanent dentition (fig. 2b) and brown in the adult permanent dentition (fig. 2c). Dental attrition as well as enamel defects were also ob-

Fig. 2. Clinical, radiographic, and histological dental manifestation of DGI-II in selected family members. a Family 1, individual IV-1, deciduous dentition showed discoloration ranging from yellow to brown and dental attrition. b Family 3, individual III-20, gray discoloration in young permanent dentition. c Family 1, individual III-8, brown discoloration in adult permanent dentition. d Family 3, individual III-20, panoramic radiograph showing bulbous-shaped crowns, partially or completely obliterated pulp chambers and canals. e Family 3, individual II-19, periapical radiograph demonstrated periapical pathology without dental caries lesions.

Fig. 3. Histological sections showing the dental manifestation of DGI-II in family members. a, b Family 1, individual II-9, photograph of permanent molar. c-g Photomicrographs of ground sections of two permanent molars showing nodular appearance that occupied the entire pulp chamber with fewer dentin tubules that have a disorganized distribution pattern. h Family 2, individual II-9, photograph of residual roots. i-j Photomicrograph of ground sections of residual roots showing completely obliterated root canals and the presence of nodular structures with irregular tubular organization.

Phenotype/Mutational DSPP Analysis of DGI Type II Families served in some deciduous teeth. The radiographic analysis demonstrated that DGI-II-affected teeth presented with bulbous-shaped crowns, partially or completely obliterated pulp chambers and root canals (fig. 2d). Periapical lesions were also identified in 6 affected members (fig. 2e). Details of the permanent dentition in adult patients were difficult to examine due to extensive tooth loss.

Ground sections of extracted teeth indicated that the dentin defects are more severe in primary teeth than in permanent teeth showing fewer dentin tubules with a disorganized distribution pattern. The dentin defects found in permanent teeth were not homogenously distributed and nodular structures were observed. Two individuals in family 1 (III-3 and II-9) showed altered dentin with a nodular appearance that occupied the entire pulp chamber in 2 molars examined (fig. 3a-g). Also, residual roots from individual II-9 in family 2 demonstrated completely obliterated root canals and the presence of nodular structures. The presence of nodular structures prior to total pulpal obliteration suggests that the pulp mineralization occurs as a result of the formation of these structures (fig. $3 \mathrm{~h}-\mathrm{j}$ ).

DSPP gene mutational analysis identified 7 known single nucleotide polymorphisms (SNPs) in the 3 families within exons 1-4 (table 2). They were: c.51+71GT(16-20) (rs34454141); c.52-74GT(11-14); c.136-29T >C (rs13131936); c.136-33T >C ( $\mathrm{rs} 13131929)$; c.202A > T, p.R68W (rs36094464); c.727G>A, p.D243N (rs3750025) and c.897A >G, p.S299S (rs2786982). None of these changes were associated with the pathogenesis of the disease in the 3 DGI-II families.

\section{Discussion}

DGI-II segregated as an autosomal dominant trait in the 3 Brazilian families ascertained. In a previous report, a Brazilian family initially presenting with DGI was shown to have a collagen type I missense mutation leading to a diagnosis of osteogenesis imperfecta, seen as ligament hyperextensibility, with DGI-I [Pallos et al, 2001]. No ligament hyperextensibility or other bony defects were observed in the examined family members reported in this study.

As previously reported by Shields et al. [1973], our study revealed variable expressivity in the occurrence and intensity of characteristics described in teeth within the same individual as well as among the individuals 
Table 1. Summary of dental and radiographic features of affected family members

\begin{tabular}{|c|c|c|c|c|c|c|c|c|c|c|c|c|}
\hline & \multicolumn{12}{|c|}{ Family 1} \\
\hline & $\begin{array}{l}\text { IV } 1 \\
05\end{array}$ & $\begin{array}{l}\text { IV } 2 \\
03\end{array}$ & $\begin{array}{l}\text { IV } 3 \\
04\end{array}$ & $\begin{array}{l}\text { III } 4 \\
27\end{array}$ & $\begin{array}{l}\text { III } 5 \\
26\end{array}$ & $\begin{array}{l}\text { III } 8 \\
23\end{array}$ & $\begin{array}{l}\text { III10 } \\
20\end{array}$ & $\begin{array}{l}\text { III } 12 \\
28\end{array}$ & $\begin{array}{l}\text { III16 } \\
22\end{array}$ & $\begin{array}{l}\text { III } 20 \\
29\end{array}$ & $\begin{array}{l}\text { II } 9 \\
58\end{array}$ & $\begin{array}{l}\text { III } 2 \\
10\end{array}$ \\
\hline Crown discoloration & + & - & + & + & + & + & - & + & + & + & + & - \\
\hline Enamel diffuse opacities & + & - & + & - & - & - & + & - & - & + & - & + \\
\hline Attrition & $3 / 3$ & - & $3 / 3$ & $2 / 3$ & $1 / 3$ & $2 / 3$ & - & $2 / 3$ & $1 / 3$ & $1 / 3$ & $1 / 3$ & - \\
\hline Root morphology alterations & + & - & + & + & + & + & - & + & + & + & + & - \\
\hline Bulbous crown & + & - & + & - & + & + & - & + & + & - & - & - \\
\hline Obliterated pulp chambers and root canals & + & - & + & + & + & + & - & + & + & + & + & - \\
\hline Periapical lesions not associated with dental pathology & - & - & - & - & - & - & - & + & - & - & + & - \\
\hline Nodules or nodules/pulp stones & - & - & - & - & - & - & + & - & - & + & - & + \\
\hline
\end{tabular}

$+=$ Feature present; $-=$ feature absent; $\mathrm{NA}=$ not applicable; $1 / 3=$ incisal attrition; $2 / 3=$ crown attrition; $3 / 3=$ total crown attrition.

Table 2. Summary of DSPP polymorphisms identified

\begin{tabular}{|c|c|c|c|c|c|c|c|}
\hline & $\begin{array}{l}\text { c. } 51+71 \mathrm{GT}(16-20) \\
\text { rs34454141 }\end{array}$ & $\begin{array}{l}\text { c. } 52-74 \mathrm{GT} \\
(11-14)^{*}\end{array}$ & $\begin{array}{l}\text { c. } 136-29 \mathrm{~T}>\mathrm{C} \\
\mathrm{rs} 13131936\end{array}$ & $\begin{array}{l}\text { c. } 136-33 \mathrm{~T}>\mathrm{C} \\
\text { rs13131929 }\end{array}$ & $\begin{array}{l}\text { c. } 202 \mathrm{~A}>\mathrm{T} \\
\mathrm{rs} 36094464\end{array}$ & $\begin{array}{l}\text { c. } 727 \mathrm{G}>\mathrm{A} \\
\mathrm{rs} 3750025\end{array}$ & $\begin{array}{l}\text { c. } 897 \mathrm{~A}>\mathrm{G} \\
\text { rs } 2786982\end{array}$ \\
\hline Family 1 & present & present & present & present & present & absent & present \\
\hline Family 3 & present & present & absent & present & present & absent & present \\
\hline
\end{tabular}

from different DGI-II families. Differences in the discoloration among deciduous and permanent teeth were also found. Affected deciduous teeth showed a more yellowish discoloration, permanent young adult teeth were more grayish, while elder adult permanent teeth were brownish. The absence of an appropriate method to identify the different discoloration patterns in DGI-II as well as other dentin diseases hampered this comparison.

The dentin alterations in ground sections of the permanent teeth were again variable especially related to the nodular structures observed in the pulp chambers. Radicular dentin canals of individuals from one of the studied families showed fewer and disorganized dentinal tubules, a feature not previously reported associated with DGI-II. In DD-II, pulp stones are frequent, but clinically and radiographically differ from those observed in primary and permanent DGI-II teeth. Some authors have suggested that DD-II and DGI-II associated with DSPP mutations are a continuum of phenotypes where DD-II represents the mildest form and DGI-II the more severe form [Hart and Hart, 2007].

The DSP-encoding region (exons 1-4) and surrounding introns were analyzed in the 3 Brazilian DGI-II families. Seven alterations were identified among the family members in the 3 families. The c.202A $>$ T alteration in exon 4 leading to a single amino acid change (p.R68W) was previously reported as a disease-causing mutation in a Swedish family [Malmgren et al., 2004]. These authors reported initial functional studies suggesting the c.202A >T-mutated DSPP was retained in the endoplasmic reticulum of odontoblasts. However, more recently, Holappa et al. [2006] reported this alteration as a polymorphism being found in 15\% of the control Finnish population. Furthermore, Hart and Hart [2007] found allele frequencies for this SNP of 6 and 16\% in Caucasian and African-American control populations, respectively. 


\begin{tabular}{|c|c|c|c|c|c|c|c|c|c|c|c|c|c|c|}
\hline \multicolumn{9}{|c|}{ Family 2} & \multicolumn{6}{|c|}{ Family 3} \\
\hline III 3 & III 4 & III 5 & III 6 & III 7 & III 8 & III 9 & III 11 & II 7 & II 5 & II 9 & II 11 & II 12 & III 20 & II 19 \\
\hline 05 & 03 & 01 & 07 & 01 & 10 & 06 & 04 & 28 & 33 & 28 & 26 & 23 & 12 & 35 \\
\hline+ & + & + & - & + & + & + & - & - & + & + & + & - & + & + \\
\hline+ & + & - & - & + & - & + & - & - & - & - & - & - & - & + \\
\hline $2 / 3$ & $3 / 3$ & $1 / 3$ & - & $1 / 3$ & $1 / 3$ & $1 / 3$ & - & - & $1 / 3$ & $1 / 3$ & $1 / 3$ & - & $1 / 3$ & $1 / 3$ \\
\hline+ & + & NA & - & + & + & + & - & - & + & + & + & - & + & + \\
\hline+ & + & NA & - & + & + & + & - & - & - & - & + & - & + & + \\
\hline+ & + & NA & - & + & + & + & - & - & + & + & + & - & + & + \\
\hline- & - & NA & - & - & - & - & - & - & - & - & - & - & - & + \\
\hline- & - & NA & - & - & - & - & - & + & - & - & - & - & - & - \\
\hline
\end{tabular}

An allele frequency of $13.6 \%$ has been reported in European populations (http://www.ncbi.hlm.nih.gov/SNP). Collectively, these findings and the data present in our study suggest that this variation is a polymorphism and not a mutation associated with the pathogenesis of DGIII. The other amino acid-altering SNP p.D243N, c.727G $>$ A, found in our study has an allele frequency ranging from 3.4 to $48.9 \%$ in different populations (http:// www.ensembl.org/Homo_sapiens/snpview). Studies by Beattie et al. [2006] have also identified other DGI-II families linked to $4 \mathrm{q} 21$ with no mutations within the DSP domain. The analysis of the dentin phosphoprotein domain encoded by exon 5 was not performed in this study due to the highly repetitive nature of this region that resulted in unsuccessful amplification. PCR optimization of the collected DNA samples is being performed for amplification.

In order to make more accurate diagnoses related to dentin diseases, a clear understanding of the genotype/ phenotype correlation is necessary. Therefore, it is critical that our database includes more families with detailed longitudinal phenotypic characterizations of their dentitions, since this is a progressive disease. Currently, very little information is available as to the detailed clinical description of DGI-II patients. When we retrospectively analyzed the descriptions of the families with identified mutations, the phenotypic details reported were inconsistent, thus limiting comparisons between different families from different geographic origins. Malmgren et al. [2004] have presented the most comprehensive clinical description of 2 families showing long-term clinical and radiographic follow-ups, as well as histopathological analysis. Since pulp chamber and canal obliteration is a progressive process, radiographic follow-ups at different ages are very useful in determining the progression of pulpal chamber and root canal mineralization. Special attention has to be given to the diagnosis of young family members. Again, Malmgrem et al. [1988] reported a 6-generation family with 2 young DGI patients (16 months and 2.5 years old) presenting with large pulp chambers and periapical radiolucencies. At older ages, the permanent teeth of these patients showed pulpal obliterations. In the Brazilian families presented here, special attention is paid to the young affected children, with a long-termed follow-up planned that will permit the developmental assessment of alteration related to tooth discoloration, attrition and differences in the clinical and radiographic features of deciduous versus permanent teeth within the same patient. Furthermore, differences between young permanent teeth and older teeth will be evaluated. Special attention must also be given to the progression of obliteration of pulp chambers and root canals throughout the subjects' life span.

\section{Acknowledgements}

We would like to thank Yixin Wu for his technical assistance with the DNA mutational analysis. We would like to specially thank all family members who participated in this study. Partial support for these studies was provided by NIDCR grant DE09875 (M.M.) and the Institute of Oral Health Research (School of Dentistry, University of Alabama at Birmingham). 


\section{References}

Beattie, M.L., J.W. Kim, S.G. Gong, C.A. Murdock-Kinch, J.P Simmer, J.C. Hu (2006) Phenotypic variation in dentinogenesis imperfecta/dentin dysplasia linked to $4 \mathrm{q} 21$. J Dent Res 85: 329-333.

Dong, J., T. Gu, L. Jeffords, M. MacDougall (2005) Dentin phosphoprotein compound mutation in dentin sialophosphoprotein causes dentinogenesis imperfecta type III. Am J Med Genet A 132A: 305-309.

-Hart S.P., T.C. Hart (2007) Disorders of human dentin. Cells Tissues Organs 186: 70-77.

-Holappa, H., P. Nieminen, L. Tolva, P. Lukinmaa, S. Alaluusua (2006) Splicing site mutations in dentin sialophosphoprotein causing dentinogenesis imperfecta type II. Eur J Oral Sci 114: 381-384.

Kerebel, B., G. Daculsi, J. Menanteau, M. Kerebel (1981) The inorganic phase in dentinogenesis imperfecta. J Dent Res 60: 1655-1660.

Kim, J.W., S.H. Nam, K.T. Jang, S.H. Lee, C.C. Kim, S.H. Hahn, J.C. Hu, J.P. Simmer (2004) A novel splice acceptor mutation in the DSPP gene causing dentinogenesis imperfecta type II. Hum Genet 115: 248-254.

-Kim, J.W, J.C. Hu, J.I. Lee, S.K. Moon, Y. J. Kim, K.T. Jang, S.H. Lee, C.C. Kim, S.H. Hahn, J.P. Simmer (2005) Mutation hot spot in the DSPP gene causing dentinogenesis imperfecta type II. Hum Genet 116: 186-191.

Kinney, J.H., J. Pople, C.H. Driessen, T.M. Breunig, G.W. Marshall, S.J. Marshall (2001) Intrafibrilar mineral may be absent in dentinogenesis imperfecta type II (DI-II). J Dent Res 80: 1555-1559.
MacDougall, M., D. Simmons, X. Luan, J. Nydegger, J. Feng, T.T. Gu (1997) Dentin phosphoprotein and dentin sialoprotein are cleavage products expressed from a single transcript coded by a gene on human chromosome 4. J Biol Chem 272: 835-842.

MacDougall, M., J. Dong, A.C. Acevedo (2006) Molecular basis of human dentin diseases. Am J Med Genet 140: 2536-2546, 2006.

-Malmgren, B., M. Lundberg, S. Lindskog (1988) Dentinogenesis imperfecta in a six-generation family. Swed Dent J 12: 73-84.

Malmgren, B., S. Lindskog, A. Elgadi, S. Norgren (2004) Clinical, histopathologic, and genetic investigation in two large families with dentinogenesis imperfecta type II. Hum Genet 114: 491-498.

-Pallos, D., P.S. Hart, J.R. Cortelli, S. Vian, J.T. Wright, J. Korkko, D. Brunoni, T.C. Hart (2001) Novel COLIA1 mutation (G599C) associated with mild osteogenesis imperfecta and dentinogenesis imperfecta. Arch Oral Biol 46: 459-470.

Rajpar, M.H., M.J. Koch, R.M. Davies, K.T. Mellody, C.M. Kielty, M.J. Dixon (2002) Mutation of the signal peptide region of the bicistronic gene DSPP affects translocation to the endoplasmic reticulum and results in defective dentine biomineralization. Hum Mol Genet 11: 2559-2565.

Ranta, H., P.L. Lukinmaa, J. Waltimo (1993) Heritable dentin defects: nosology, pathology, and treatment. Am J Med Genet 45: $193-$ 200.

Rao, S., C.J. Witkop (1971) Inherited defects in tooth structure. Birth Defects 7: 153-184.

Shields, E.D., D. Bixler, A.M. El-Kafrawy (1973) A proposed classification for heritable human dentine defects with a description of a new entity. Arch Oral Biol 8: 543-553.
Sreenath, T., T. Thyagarajan, B. Hall, G. Longenecker, R. D’Souza, S. Hong, T. Wright, M. MacDougall, J Sauk, A Kulkarni (2003) Dentin sialophosphoprotein knockout mouse display widened predentin zone and develop defective dentin mineralization similar to human dentinogenesis imperfecta-III. J Biol Chem 278: 24874-24880.

Witkop, C.J., C.J. MacLean, P.J. Schmidt, J.L. Henry (1966) Medical and dental findings in the Brandywine isolate. Ala J Med Sci 3: 382403.

Witkop, C.J. (1975) Hereditary defects of dentine. Dent Clin N Amer 19: 25-45.

Witkop, C.J. (1989) Amelogenesis imperfecta dentinogenesis imperfecta and dentin dysplasia revisited: problems in classification. J Oral Path 17: 547-553.

Xiao, S., C. Yu, X. Chou, W. Yuan, Y. Wang, L. $\mathrm{Bu}, \mathrm{G} . \mathrm{Fu}, \mathrm{M}$. Qian, J. Yang, Y. Shi, L. Hu, B. Han, Z. Wang, W. Huang, J. Liu, Z. Chen, G. Zhao, X. Kong (2001) Dentinogenesis imperfecta 1 with or without progressive hearing loss is associated with distinct mutations in DSPP. Nat Genet 27: 201-204.

Zhang, X., J. Zhao, C. Li, S. Gao, C. Qiu, P. Liu, G. Wu, B. Qiang, W.H.Y. Lo, Y. Shen (2001) DSPP mutation in dentinogenesis imperfecta Shields type II. Nat Genet 27: 151-152.

Zhang, G.X., L. Chen, J. Liu, Z. Zhao, E. Qu, X. Wang, W. Chang, C. Xu, Q.K. Wang, M. Lu (2007) A novel DSPP mutation is associated with type II dentinogenesis Imperfecta in a Chinese family. BMC Med Genet 8: 52. 